\title{
MAPPING RIVERBED SEDIMENT SIZE FROM SENTINEL 2 SATELLITE DATA
}

G. Marchetti ${ }^{1 *}$, S. Bizzi ${ }^{2}$, B. Belletti ${ }^{3}$, B. Lastoria ${ }^{4}$, F. Comiti ${ }^{1}$ and P.E. Carbonneau ${ }^{5}$

${ }^{1}$ Faculty of Science and Technology, Free University of Bozen, Bozen, Italy

2: Department of Geosciences, University of Padova, Padua, Italy

3: CNRS-EVS, ENS-Lyon, University of Lyon, France

4: Institute for Environmental Protection and Research, Rome, Italy

5: Department of Geography, Durham University, Durham, UK

*: Corresponding author. Email: Giulia.Marchetti@natec.unibz.it

The paper is a non-peer reviewed preprint submitted to EarthArXiv. This work was submitted to Earth Surface Processes and Landforms journal for peer review. 


\begin{abstract}
A comprehensive understanding of river dynamics requires quantitative knowledge of the grain size distribution of bed sediments and its variation across different temporal and spatial scales. Several techniques are already available for grain size assessment based on field and remotely sensed data. However, the existing methods are only applicable on small spatial scales and on short time scales. Thus, the operational measurement of grain size distribution of river bed sediments at the catchment scale remains an open problem. A solution could be the use of satellite images as the main imaging platform. However, this would entail retrieving information at sub-pixel scales.

In this study, we propose a new approach to retrieve sub-pixel scale grain size class information from Copernicus Sentinel-2 imagery building upon a new image-based grain size mapping procedure. Three Italian gravel-bed rivers featuring different morphologies were selected for Unmanned Aerial Vehicle (UAV) acquisitions coupled to field surveys and lab analysis meant to serve as ground truth grain size data. Grain size maps on river bars were generated in each study site by exploiting image texture measurements, upscaled and co-registered with Sentinel-2 data resolution.

Relationships between the grain sizes measured and the reflectance values in Sentinel-2 imagery were analyzed by using a machine learning framework. Results show statistically significant predictive models (MAE of $\pm 8.34 \mathrm{~mm}$ and $R^{2}=0.92$ ). The trained model was applied on $300 \mathrm{~km}$ of the Po river in Italy and allows to detect grain size longitudinal variation and to identify the gravel-sand transition occurring along this river length.

Our proposed approach based on freely available satellite data calibrated by low-cost automated drone technology can provide reasonably accurate estimates of surface grain size classes, in the range of sand to gravel, for bar sediments in medium to large river channels, over lengths of hundreds of kilometers.
\end{abstract}

\title{
1. INTRODUCTION
}

Linkages among bed sediment size, river morphology and ecological dynamics (Ferguson et al., 1996; Pitlick et al., 2008; Pizzuto, 1995; Rice, 1999; Rice and Church, 2001) call for grain size assessment carried out at large spatial scales, i.e., over most of the channel 
network (Dugdale et al., 2010). In fact, river systems and their biota respond and behave at large temporal and spatial scales (Fausch et al., 2002). However, the bulk of our scientific measurement and monitoring work occur at much smaller spatial scales which are usually further constrained by short temporal scales. These considerations are valid also for particle size measurement. Beside field-based surveys, remotely-sensed approaches to grain size mapping have been an active focus of research for over a decade allowing for the development of more objective and rapid methods (e.g. Black et al., 2014; Buscombe et al., 2010; Buscombe and Masselink, 2009; Carbonneau et al., 2018, 2004a, 2004b, 2005; Detert and Weitbrecht, 2012; Dugdale et al., 2010; Graham et al., 2005, 2010; Rubin, 2004; Verdú et al., 2005; Woodget et al., 2018). Overall, a range of methods are now available, each with well-documented errors, meaning that an operational characterisation of both dry and submerged gravels (water clarity permitting) is now possible with a range of airborne and terrestrial remote sensing methods. Unmanned Aerial Vehicles (UAV, also referred to as drones) technology allows for the collection of high resolution ( $\mathrm{mm}$ to sub-mm) imagery suitable for the measurement of surficial particle size distribution (e.g. Detert and Weitbrecht, 2012; Graham et al., 2005; Rubin, 2004), or SfM-photogrammetry point clouds useful to directly extract surficial grain sizes (Vázquez-Tarrío et al., 2017; Woodget et al., 2018). Although the current UAV technical properties would allow for low-cost measurement of several river attributes over kilometric scales, this technology cannot extend river surveys up to large catchment, regional or continental scales, and acquisitions at high temporal frequencies are difficult.

A common approach for particle size estimation is to establish empirical correlation between some statistical properties of an image patch, such as co-occurrence textures or semivariance, and a measure of grain size such as median ( $\left.D_{50}\right)$ or $D_{84}$ values (e.g. Buscombe and Masselink, 2009; Carbonneau et al., 2004b). The hypothesis behind this approach is that, among several parameters such as shape, size, internal structure and spatial organization, surface roughness affects the light backscatter and can be exploited to discriminate sediment size classes. In fact, single scattering albedo of the smaller particles is greater than the one of the bigger particles (Nash and Conel 1974, Pilorget et al., 2015, 2016). This has been demonstrated through laboratory experiments by Pilorget et al. $(2013,2015,2016)$ who's' outcomes suggest that in the near-infrared region, even a small variation in the size of a mixture of particles with a given composition and scattering properties tends to control the overall photometric behaviour. In Pilorget et al., 2016 the 
macroscopic roughness parameter, as defined by Hapke 1984, has been shown evolving with the wavelength and being to first order correlated with the absorptivity of the particles, thus mostly corresponding to a measurement of the particles shadowing. Additional support for this observation can be found in Carson et al. (2015), who finds from a physically robust modelling study that fine granular soils composed of quartzite and magnetite have a Bidirectional Reflectance Distribution Function (BRDF) intensity which is inversely proportional to wavelengths and therefore results in a systematically higher reflectance at longer infrared wavelengths for all view angles. Furthermore, Robinson and Friedman (2005) find that the dielectric constant of materials composed of spherical particles can be affected by the geometry of the sphere packing arrangements. This finding is relevant since it is well established in electromagnetism theory that the intensity of reflection of an electromagnetic wave is proportional to the dielectric constant of the reflecting material (Marion and Heald, 1980). Taken together, these observations do suggest that, for longer wavelengths, particle size for granular soils may affect the intensity of reflected radiation. This approach has been widely applied with high resolution imagery $(\mathrm{mm}-\mathrm{cm} /$ pixels) where there is an implicit assumption that surface properties of sediment will affect image properties even if only using standard RGB imagery. However, there is very little literature with sub-pixel $\left(10^{-2}\right.$ to $10^{0} \mathrm{~m} /$ pixel) imagery for grain size mapping. Black et al., 2014 attempted to use hyperspectral data from aircraft technology (image resolution of 3 $\mathrm{cm} /$ pixel). Results of this work suggest that sandy patches reflect more brightly than larger particles in longer wavelengths of red and infrared. Satellite data, despite their low spatial resolution (m/pixel), have been used in sub-pixel methods to study landscape units with characteristic dimensions below 100 m or even below 10 m (Busetto et al., 2008; Verhoeye and De Wulf, 2002). A recent study of Purinton and Bookhagen 2020 showed that radar amplitude collected by several satellites, with different wavelength and resolution, have a good potential for mixed sand- and gravel-bed river sediment identification.

In this work, we aim to investigate the potential of retrieving sub-pixel scale grain size information from Copernicus Sentinel-2 imagery. The approach combines the low-cost UAV imagery to calibrate robust linear correlations between the grain sizes on dry exposed river bars and reflectance values in Sentinel-2 imagery. We hypothesise that: (i) there is an inverse correlation between grain size and Sentinel-2 reflectance data; (ii) this correlation, calibrated with UAV imagery and field data, makes possible to infer grain size from Sentinel- 
2 reflectance data; (iii) this allows us to detect grain size longitudinal variation and to identify the gravel-sand transition occurring along $300 \mathrm{~km}$ of the Po river in Italy. 


\section{METHODOLOGY AND METHODS}

\subsection{Study areas}

Six study sites, correspondent to exposed sediment bars, were selected along three Italian gravel-bed rivers: Po, Sesia and Torrente Bonamico (Figure 1). The choice of the sites was driven by the need of having a heterogeneous dataset in terms of grain size and lithology and large (>100 $\mathrm{m}^{2}$, to account for the Sentinel-2 pixel size $10 \mathrm{~m} \times 10 \mathrm{~m}$ ), homogeneous and unvegetated sediment bars. Four study sites lie in Northern Italy: three on the Po River and one on the Sesia River. The Po River is the largest Italian river, both in terms of length (652 $\mathrm{km}$ ) and drainage basin area (about 74,000 $\mathrm{km}^{2}$ ). Along its length, the Po River displays a wide spectrum of channel patterns as consequence of both natural and anthropic factors, including single-thread sinuous and meandering, transitional and multi-thread braiding patterns. The Po valley is one of the most populated and productive areas of Italy, so that human activities have deeply modified the Po river behavior over the centuries (Gumiero et al., 2009, Marchetti 2002, Surian and Rinaldi 2003). River bars are mostly dominated by gravel down to the confluence with the Ticino River. Downstream of this section, the Po channel becomes narrower with a sinuous to meandering pattern, and alternate and point bars mainly composed of sand. The three study sites along the Po River are located upstream (site P1, Fig. 1) and downstream of the Ticino confluence (sites P2 and P3, Fig. 1).

The Sesia River (basin area of around $2920 \mathrm{~km}^{2}$ ) is an important Alpine tributary of the Po River, which feeds the latter with high volumes of bedload, ranging in size from coarse gravels to cobbles. Morphologically, once the Sesia leaves the confined reaches within the Alps, it features island-braiding channel pattern, which downstream evolves into a single thread meandering channel. The study site on the Sesia River is located along the islandbraiding reach (site S1, Fig.1), characterized by a cobble bed, close to the town of Arborio. Finally, the last two study sites (B1 and B2 in Fig.1) were selected along the Bonamico River, a short length watercourse $\left(18 \mathrm{~km}\right.$ ) draining a small-sized catchment (about $136 \mathrm{~km}^{2}$ ) flowing in a very steep valley in the Calabria Region (Southern Italy). This watercourse features a large supply of coarse sediments (gravel and cobbles) and a marked braiding pattern. 

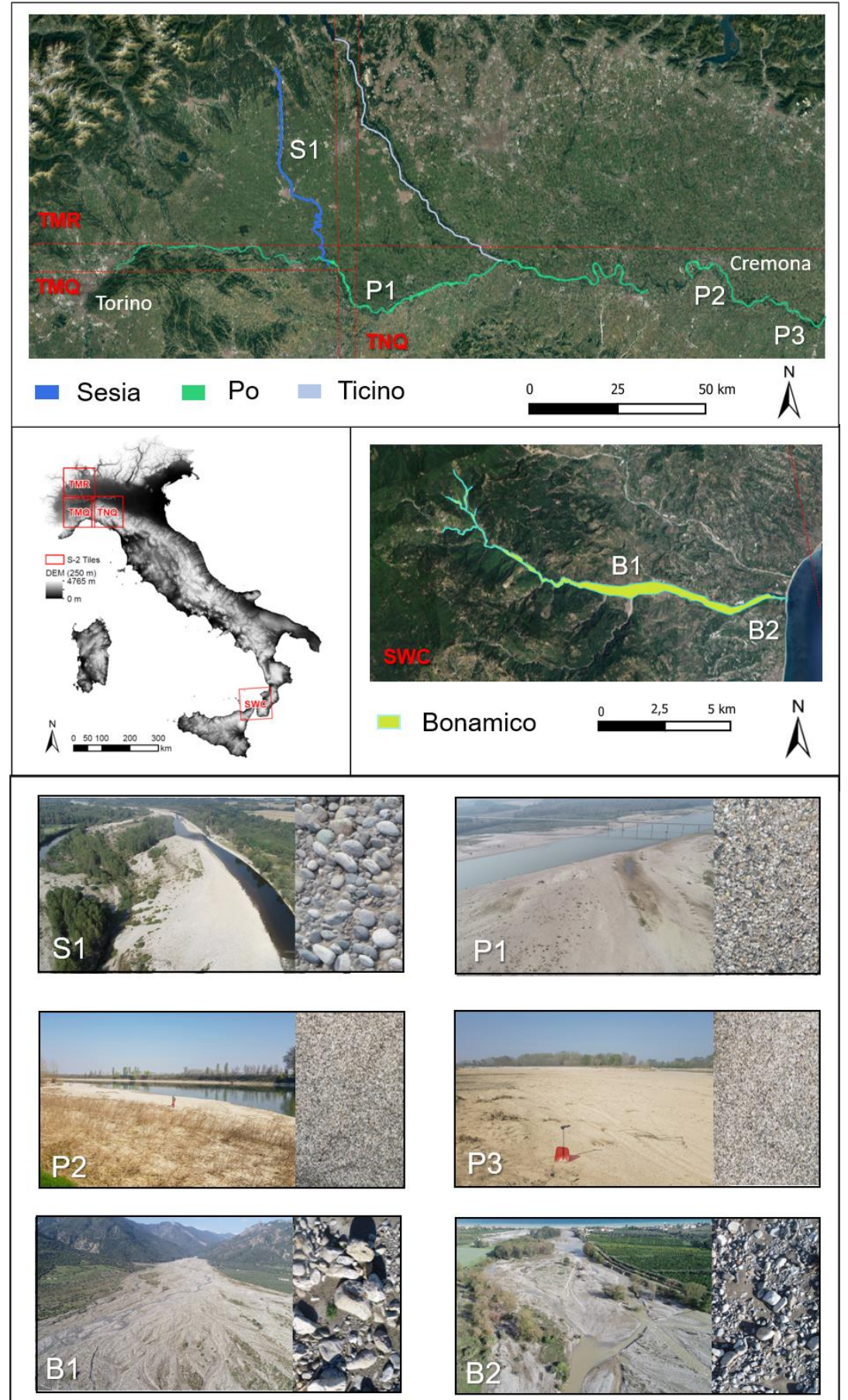

Figure 1. Study area. Location of the 6 surveyed bars along the Po, Sesia and Bonamico rivers and a photo of each bar and their sediments.

Figure 2 reports the methodological workflow embraced by this study and includes a i) ground-truthing step of grain size analysis on the study sites; ii) a satellite-based analysis on the same study sites, and iii) an application of the grain size prediction model derived from steps i) and ii) to sediment bars selected along $300 \mathrm{~km}$ of channel length in the Po 
River from Turin city, in Piedmont region, to Casalmaggiore city, province of Cremona, in Lombardy region. These steps are illustrated in detail in the following sections. The overall framework was conducted in QGIS and Python.

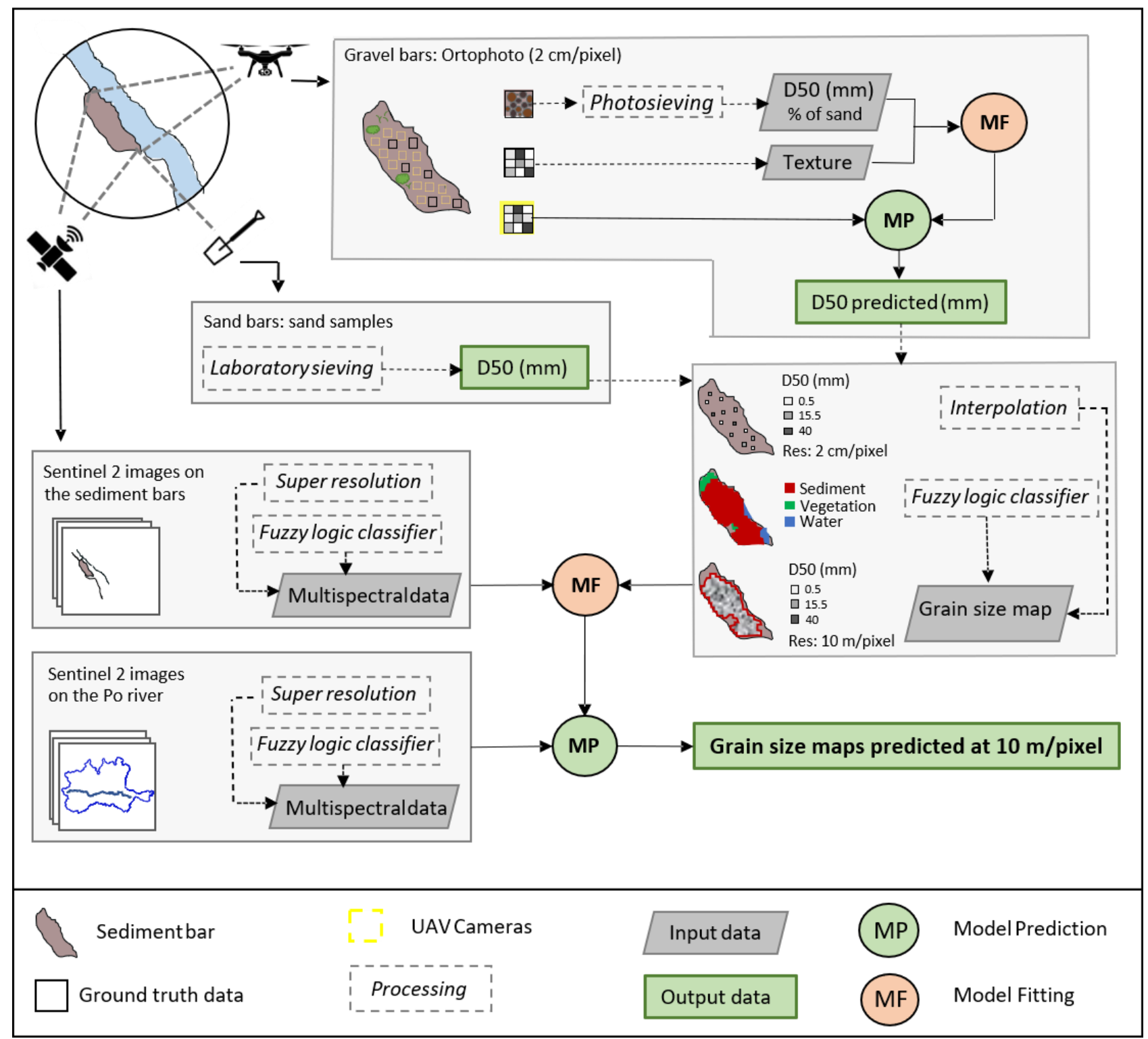

Figure 2. The methodological workflow includes: the ground-truthing data collection carried out for gravel-dominated bars and for sand-dominated bars. Each step is applied to each sediment bar selected as study site, reported in figure 1. For each sediment bar the outcome is a grain size map generated at $10 \mathrm{~m} /$ pixel. This map is combined with Sentinel 2 multispectral data collected in the same site and used for Model Fitting. The Fuzzy logic classifier is used to isolate sediment pixels only. Afterwards, the model was applied on sediment river bars selected along $300 \mathrm{~km}$ of the Po river. Multispectral sentinel 2 data are the input variable and the model results in grain size maps predicted in each sediment bar selected exploiting the Fuzzy logic classifier. 


\subsection{Ground truthing data acquisition and analysis}

Ground-truthing data for sediment size distribution on river bars were collected at different times and with different techniques, exploiting both high resolution drone imagery and field sampling with subsequent lab sieving. Two different procedures were then applied to grain size data measurement to obtain a grain size map on the entire sediment bars, used as training data for machine learning models.

Drone flights were conducted in September 2018 in the Sesia and Po rivers (sites S1 and P1; Fig. 1, and in November 2018 in the Bonamico River (sites B1 and B2; Fig. 1). Surveys were conducted by a DJI Phantom 4 Pro drone for images acquisition and by a Trimble R10 RTK-GPS for ground target data collection at cm-accuracy. The UAV images were acquired at $80 \%$ forward overlap and $50 \%$ sidelap, at different altitudes: one flight at around $50 \mathrm{~m}$ above ground level to collect RGB imagery of the whole site, whereas other flights were conducted at $20 \mathrm{~m}$ and further near ground at 5-7 m, according to the 'robotic photosieving' framework proposed by Carbonneau et al., 2018.

Agisoft Metashape software was used to process all UAV images and to produce orthophotos with a spatial resolution of $2 \mathrm{~cm}$. In the orthophoto process generation the blending mode and hole fitting mode were unchecked to minimize blurring and/or distortion effects. The near ground images were used to detect particles down to a size of about 3 $\mathrm{mm}$, over an area of around $100 \mathrm{~m}^{2}$. Low altitude images were collected to cover the whole grain size range found on river bars. From each image, an automated photosieving process, using PebbleCounts software (Purinton and Bookhagen, 2019), was used to determine surface grain sizes and sand percentage. The presence of fine particles in the interstitial area between gravels affects image texture thus it needs to be accounted for. To include the sand percentage data (\% sand), the final D50 percentile value was calculated as $D_{50} \times(1-\%$ sand $)$. A total of 48 particle percentiles values (D50) were measured in all sites. To enlarge the dataset, a texture-based grain size mapping approach was used to derive grain size measurement from the UAV orthoimage texture. The idea behind is to use $\mathrm{cm}$-scale resolution UAV orthophotos to generate grain size maps of the entire sediment bars under study.

The next steps of the analysis were conducted in Python with emphasis on the scikit-learn and scikit-image libraries (Pedregosa et al., 2011; Walt et al., 2014) which offer high-level routines for machine learning and image processing, including texture calculation. Texture- 
based grain size mapping approaches are well established in literature (Woodget et al 2018, Carbonneau and Lane 2005) showing strong linear relationship between surface grain size and the texture properties of remotely sensed data. A range of 33, 51 and 101 kernel window sizes were used, based on previous experience (Carbonneau 2005, Black et al., 2014) to calibrate the surface grain size determination models. The window for the Gray Level Cooccurrence Matrix (GLCM) calculation, needed for dissimilarity algorithm application, was centered at the $X Y$ location of the ground truth data collected by the photosieving technique. A linear model was used to fit the dissimilarity extracted values and the D50 diameter with a 5-fold cross validation, later used to generate the grain size map of each sediment bar. As noted by Woodget et al., 2018, often the SfM orthorectification process limits the strength of the results obtained with texture-grain size approach. To avoid the inclusion of blurred patches and limit the disturbance linked to different light conditions between different lines of flight, the texture-grain size approach was limited the analysis to tiles of $8 \times 8 \mathrm{~m}$ cut on the orthophoto centered on the $X Y$ cameras positions. After a manual selection of tiles not contaminated by water and vegetation, dissimilarity values were extracted for each tile, with a moving window of $101 \times 101$ pixels. The texture-grain size model previously calibrated was thus used in prediction and the median diameter value calculated in each $8 \times 8 \mathrm{~m}$ tile was taken as reference grain size percentile for the correspondent $X Y$ sampling location. Moving to QGIS, the dataset was interpolated exploiting the GRASS v.bspline command, to generate a grain size map for each site with the same resolution (10 m/pixel) and coordinate system of Sentinel 2 data. Resulting grain size maps were readily comparable with reflectance values of Sentinel 2 images since they overlap perfectly with the corresponding Sentinel 2 pixels.

In addition to UAV-based ground-truthing on gravel bars, in April 2021 field samplings in the Po River were carried out to enlarge the dataset to the sand-dominated bars (sites iii and iv, Fig. 1). For such sediment size, the application of the photosieving technique is not feasible, and laboratory analysis were necessary on sediment samples. Two sand bars downstream the confluence with the Ticino River (sites P2 and P3; Fig. 1) were selected for samples collection, characterized by homogeneous grain size distribution through the entire bar. A total weight of $2.4 \mathrm{~kg}$ for site P2 and $3.6 \mathrm{~kg}$ for site P3 were sieved to measure particles dimensions. A grain size map at $10 \mathrm{~m}$ resolution was generated for each bar by assigning the median diameter derived from the two field samples, by assuming a uniform superficial grain size distribution, as assessed in the field. 


\subsection{Sentinel 2 data extraction}

Sentinel 2 multispectral data were downloaded from the Copernicus services data hub (https://scihub.copernicus.eu/) for each selected site. Acquisition time was selected close to the field work date, avoiding cloudy days with no visibility. Additional checks were also performed to ensure no rainfall occurred in the 3 days prior to Sentinel image acquisitions. Furthermore, discharge values from the nearest upstream gauging station and precipitation records were checked to control hydraulic conditions. Indeed, wet soils have a much higher dielectric constant and so appear much darker. This means that the approach tested here has to be restricted to dry soils. Based on these criteria, Sentinel 2 images were downloaded at level 2A (with full atmospheric correction). The output products of the atmospheric correction step are: four bands at $10 \mathrm{~m}$ : $490 \mathrm{~nm}$ (B2), $560 \mathrm{~nm}$ (B3), $665 \mathrm{~nm}$ (B4), $842 \mathrm{~nm}$ (B8); nine bands at $20 \mathrm{m:} 490 \mathrm{~nm}$ (B2), $560 \mathrm{~nm}$ (B3), $665 \mathrm{~nm}$ (B4), $705 \mathrm{~nm}$ (B5), $740 \mathrm{~nm}$ (B6), $783 \mathrm{~nm}$ (B7), $865 \mathrm{~nm}$ (B8a), $1610 \mathrm{~nm}$ (B11), $2190 \mathrm{~nm}$ (B12); three bands at $60 \mathrm{m:}$ $443 \mathrm{~nm}$ (B1), $945 \mathrm{~nm}$ (B9) and $1375 \mathrm{~nm}$ (B10). The Super resolution algorithm available as the Sen2Res plugin for the ESA SNAP open-source software, was used to super resolve the available bands at $10 \mathrm{~m}$ resolution (Brodu et al., 2017). In this work bands 1,9 and 10 were not used because were designed to detect atmospheric quantities, thus the 10 bands available from VIS to SWIR region constituted the reflectance dataset. The super-resolution method has a high computational cost but it was necessary in this work, in accordance with the requirement needed the Fuzzy logic classifier of Carbonneau et al., 2020.

Fuzzy classification of the Sentinel-2 imagery was used to select field samples generated from the UAV work described above. Our initial UAV grain size maps could include sediment patches that have a small percentage of water or vegetation which is well below the size of a single Sentinel-2 pixel. Given that these 2 components interact strongly with infrared radiation, their presence at a sub-Sentinel-2 pixel scale can substantially degrade the quality of a grain-size mapping process based on infrared reflection. The last step of the procedure was therefore to filter and select only pixels belonging to dry sediments clear of vegetation. The fuzzy classifier infers sub-pixel composition with median errors ranging from -0.05 to 0.02 and mean absolute errors ranging from 0.14 to 0.21 and predicts the membership percentage of three classes of pixels: water, sediment and vegetation. This allowed for the selection of a total of 4597 sediment pixels, later available to train the model, of which 2404 
belong to the sand class (amount of pixels on the sand bars P2 and P3) and 2193 belong to the gravel sediment class (amount of pixels on the gravel dominated bars S1, P1, B1, B2).

\subsection{Models training and assessment}

The dataset for the development of the grain size mapping model is composed of 4597 grain size values (D50 percentile) and 4597 corresponding radiance values registered from Sentinel 2 in 10 bands, which correspond to $4597^{\star} 10 \mathrm{~m}^{2}$ of exposed, unvegetated sediment bars (Fig 1).

First, the spectral signature of each study site and that of each sediment class was analyzed to investigate the potential of the dataset collected and to test the hypothesis of an inverse correlation between grain size and reflectance data of Sentinel 2. The spectral signature of soils follows a shared pattern along the electromagnetic spectrum, differing based on several parameters, such as surface roughness. To build the spectral signatures, the average of the reflectance data in each sediment bar was calculated and plotted against the wavelengths. The same plot was done by splitting the dataset in four grain size classes, from fine sand to coarse cobbles, and averaging the radiance values of each class, in each wavelength available.

Second, supervised machine learning techniques were used for model training in Python. Response variables are the 4597 grain size values, and predictor variables are the 10 bands corresponding reflectance values. Regression models were trained, both linear (Huber regression) and nonlinear (Random Forest, DNN). The Mean Error (ME) and Mean Average Error (MAE) were applied to a $20 \%$ portion of the dataset set aside and not used in model training. The resulting error metrics are used as performance metrics to select the most meaningful model. Alternative model configurations were tested by selecting the most meaningful bands as candidate predictors for the observed $D_{50}$.

Furthermore, logistic regression was used as a binary classification algorithm to distinguish sand and gravel. The threshold was set at $2 \mathrm{~mm}, 22.6$ and $32 \mathrm{~mm}$, to discriminate between fine (sand) and coarse (gravel) particles in the dataset, following the Wentworth scale. Model assessment was evaluated looking at the confusion matrix scores. 


\subsection{Model prediction}

The regression model derived as explained above was applied to predict grain size of exposed sediment bars selected along $300 \mathrm{~km}$ of the Po River (Figure 1). The aim was to test the model for large scale superficial grain size mapping and to validate the model in terms of transition from gravel to sand dominated bars. The same procedure described in 2.2, based on the Fuzzy logic classifier of Carbonneau et al., 2020, was applied on the Po river corridor to select Sentinel-2 pixels corresponding to sediment bars. Figure 3 reports an example of two river reaches, selected in a wandering reach and in a sinuous reach classified in the three fuzzy members water, sediment and vegetation. Each pixel was assigned to each class with a probability (value from 0 to 100), resulting from the fuzzy logic approach. Only pixels classified with a score greater than 95 were used in this work for the model prediction.

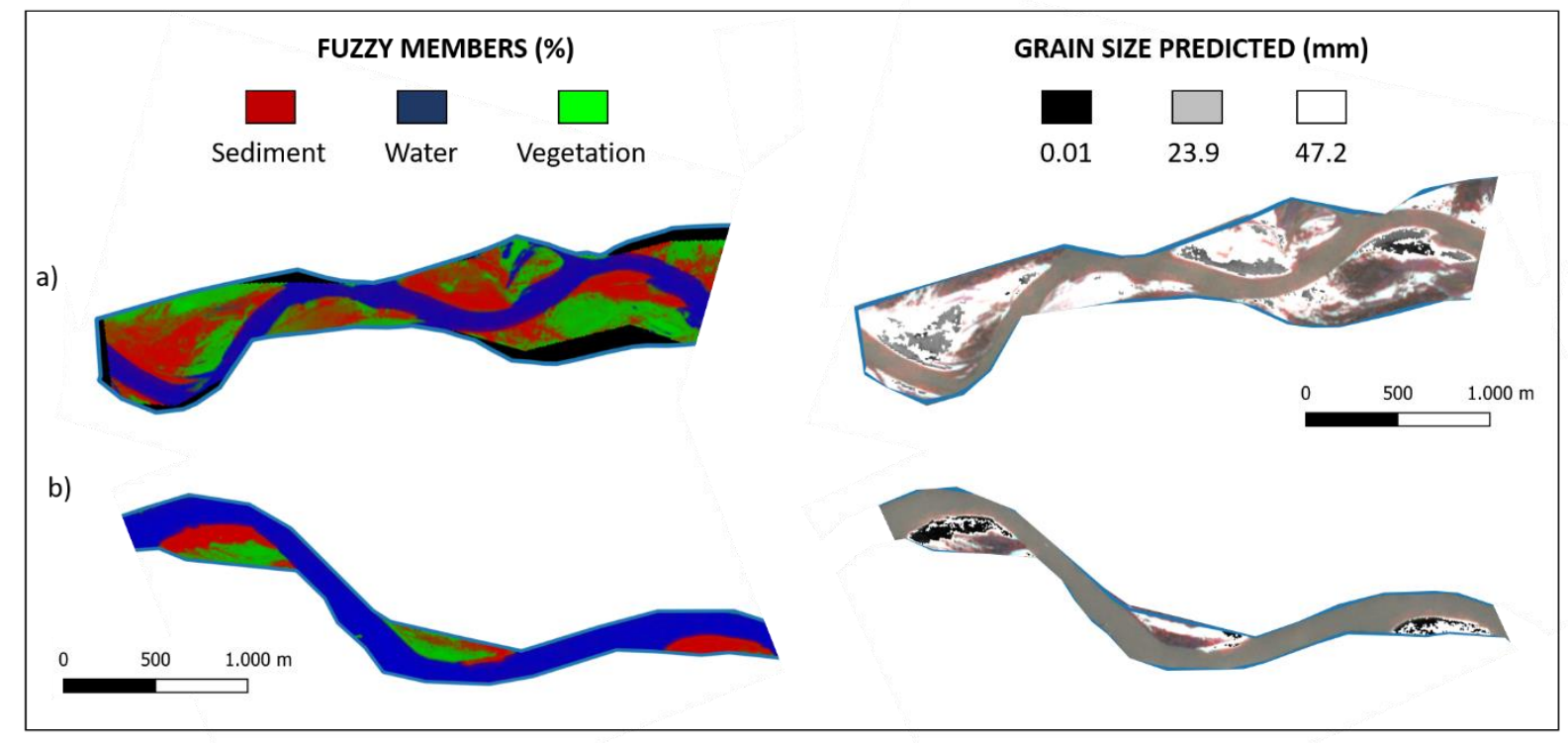

Figure 3. Fuzzy logic classifier. Figure 3 a) shows, on the left, river corridor classified in the Fuzzy logic members, in a wandering reach, upstream the Ticino River confluence; on the right the same river reach on a Sentinel 2 image, where results of the model application ( $D^{50}$ predicted) are shown in a gray scale color in correspondence of Sentinel 2 pixel selected as sediment; Figure 3 b) shows the same as in a) on a sinuous river reach close downstream the Ticino River confluence, close to Isola Serafini dam.

To visualize the longitudinal grain size variation predicted, a distance value was assigned to each pixel identified as sediment. To do that, a vector line following the river channel was built in QGIS, starting at Torino city, and its vertex were stepped up and extracted. The 
cumulative distance value was automatically calculated for each vertex, together with its projected coordinates (mgrs grid zone: UTM 32T). The resulting output was a raster where each pixel selected as sediment member with a probability greater than 95 has been assigned a distance value and a predicted $D_{50}$ value.

\section{RESULTS}

\subsection{Texture-based model for grain size estimation from UAV images}

Table 1 reports the ground truth data obtained (mean value of the total samples collected per site) and the area covered in each site. As it can be noticed, the grain size range goes from sand to gravel and cobble class. The median diameter of the site P1 selected on the Po river upstream, at around $100 \mathrm{~km}$ from Torino city, is $35 \mathrm{~mm}$. The median diameter of the downstream sites P2 and P3, close to Cremona city, ranges from 0.43 to $0.35 \mathrm{~mm}$. These bars are composed of sand with layers of silt-clay deposited from residual standing water. The site S1, selected along the Sesia river Arborio, is characterized by a coarse sediment bar with a cobble bed $\left(D_{50}=42 \mathrm{~mm}\right)$. Along the Bonamico the selected sites $B 1$ and B2 are featured by a $D_{50}$ of $33 \mathrm{~mm}$ and of $42 \mathrm{~mm}$, respectively.

Table 1. Ground truth data measured by photosieving technique (gravel samples) and sieving in the laboratory (sand samples)

\begin{tabular}{lll}
\hline Site & Area $\left(\mathrm{km}^{2}\right)$ & D50 $(\mathrm{mm})$ \\
\hline S1 & 0.06 & 42.4 \\
P1 & 0.27 & 34.9 \\
P2 & 0.22 & 0.43 \\
P3 & 0.19 & 0.35 \\
B1 & 0.25 & 32.8 \\
B2 & 0.12 & 42.3 \\
\hline
\end{tabular}

In figure $4 a$ the $48 D_{50}$ values extracted by UAV-based photosieving on all study gravel bars are plotted against the corresponding texture dissimilarity values (see section 2.2). A linear relationship between median diameters and the texture metric is apparent. 
a)

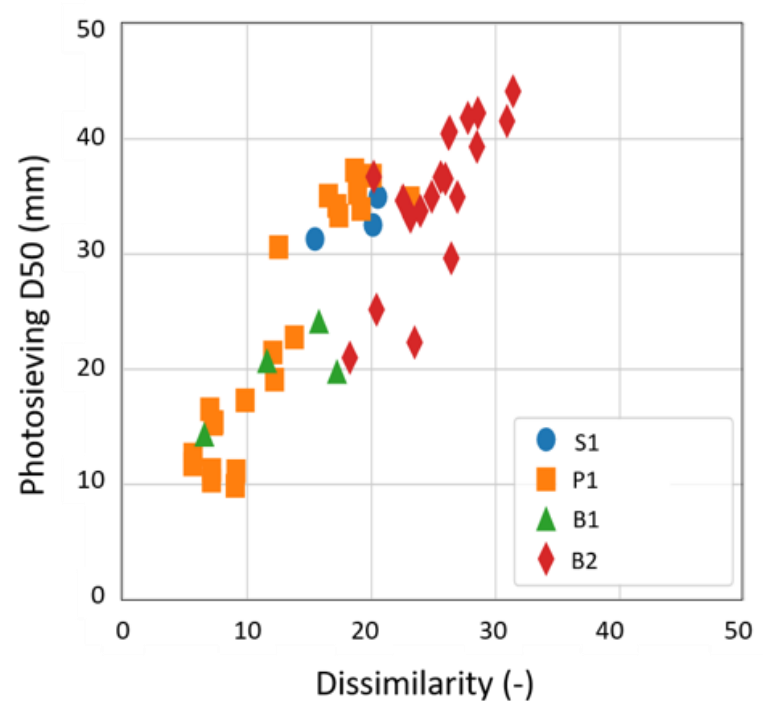

b)

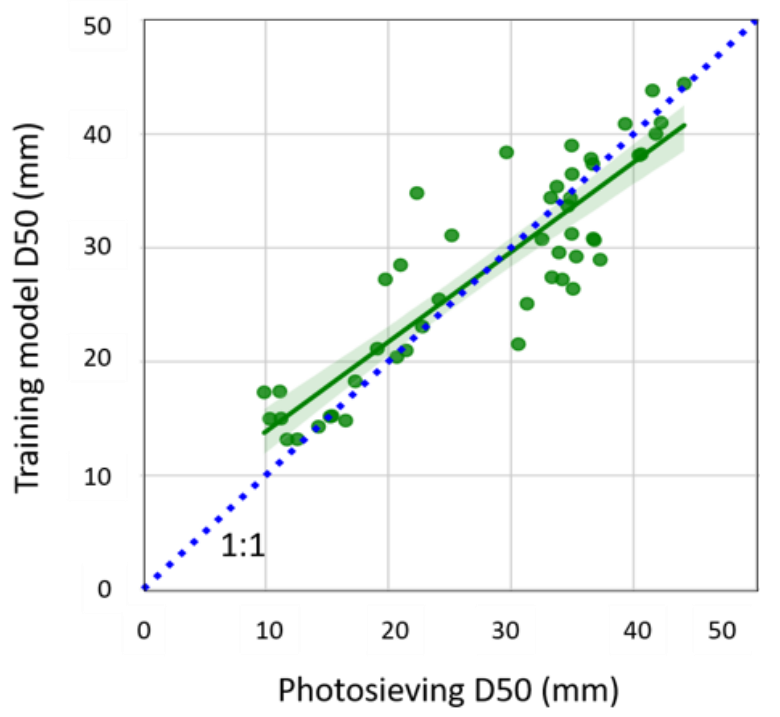

Figure 4. The results of the texture-based model (gravel bars): a) plot of Dissimilarity (measured on $101 \times 101$ pixels window size) vs $D_{50}(\mathrm{~mm})$; b) plot of the observed vs predicted $D_{50}$ values

As expected, as the median diameter increases the texture of the image window, and hence the difference in brightness between adjacent pixels, increases. A linear model was used to fit the data, with a 5 -fold cross validation. Figure $4 \mathrm{~b}$ shows the observed vs predicted values, and $a R^{2}=0.78$ is obtained. The Mean Absolute Error (MAE) resulting from the 5 -fold cross validation results to be $5.5 \mathrm{~mm}$ with a standard deviation of \pm 0.23 . This model was used to predict grain size data on the entire river bars and generate a grain size map at $10 \mathrm{~m}$ resolution (Sentinel 2 resolution), thus increasing the sampling dataset up to 4597 values.

\subsection{Spectral signatures from Sentinel-2 images}

Figure 5 shows the analysis made on the 4597 grain size values ( $D_{50}$ values) and the corresponding Sentinel 2 radiance values super resolved at $10 \mathrm{~m}$ resolution, made to investigate the potential of the dataset collected and to test the hypothesis of an inverse correlation between grain size and reflectance data of Sentinel 2. 

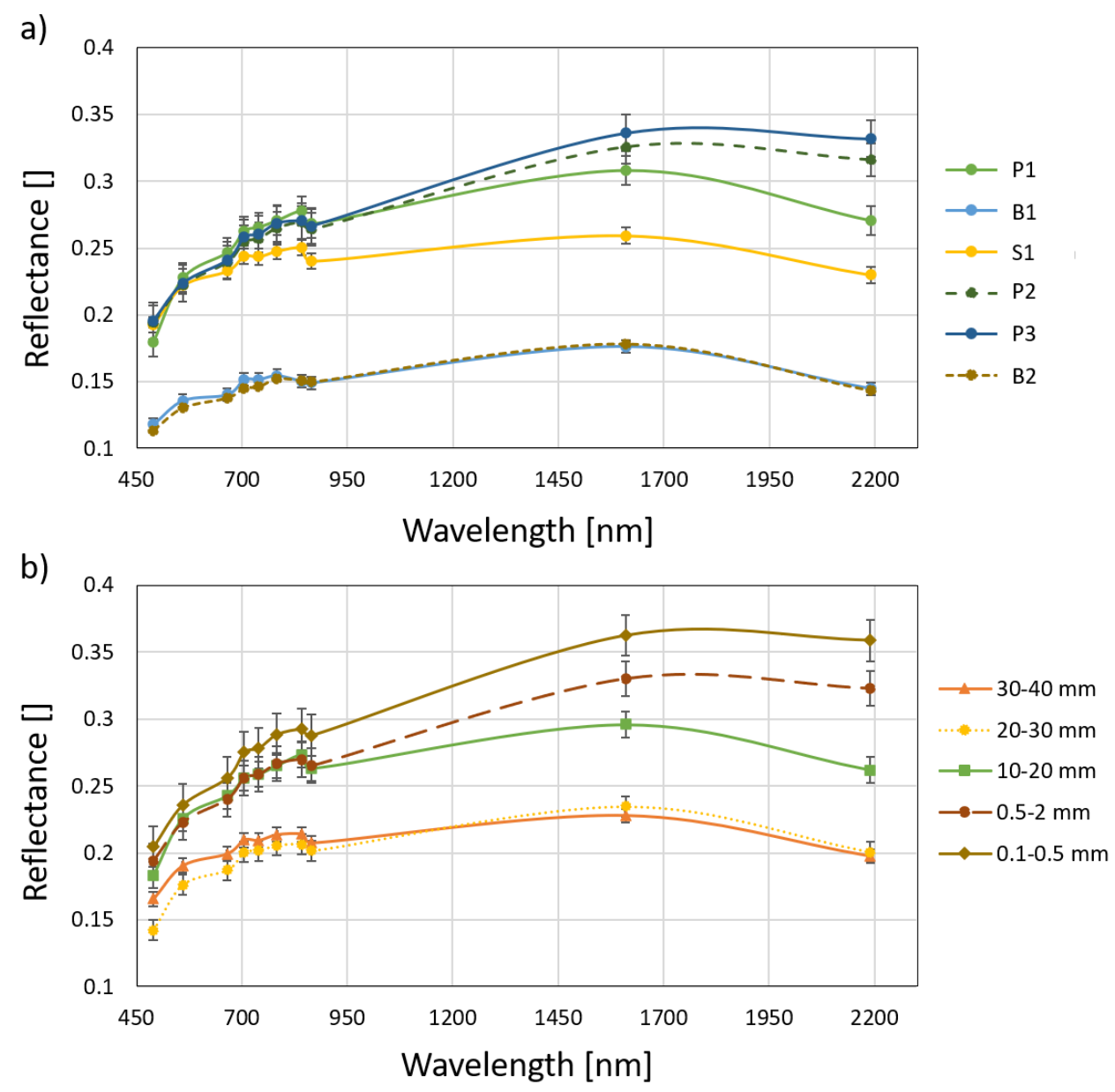

Figure 5. Sentinel-2 spectral signatures. a) spectral analysis of each site b) signature analysis of each sediment class. On the $y$ axis are reported the radiance values, on the $x$ axis the electromagnetic spectrum discretized according to the 10 Sentinel 2 bands available. Different colors are used to show the spectral signature of the different study sites (a) and of different grain size classes (b).

In figure 5 a the average of the reflectance value of each sediment bar is plotted versus each wavelength. Overall, spectral signatures follow similar trends at all sites, as expected for soil spectral response (Swain and Davis 1978). Sand-dominated sites, (D50 about $0.5 \mathrm{~mm}$, obtained from the lab sieving analysis), have the highest reflectance over the whole spectrum. As grain size increases ( $D_{50}$ in the range of $25-40 \mathrm{~mm}$ ) the overall spectral signature has lower values. Gravel bars in the Sesia and Po rivers (sites S1 and P1) feature a median diameter (obtained from UAV-based photosieving) of 30-40 mm, and plot very close to the sand sites in the VIS region but are well distinguishable in the NIR and SWIR region. Gravel bars in the Bonamico River (sites B1 and B2) feature $D_{50}$ values in the range 30-40 mm - i.e. very similar to the Po and Sesia gravel bars - but differ considerably in terms of spectral signature. 
Figure 5b illustrates the clear effect of grain size on the spectral signature. In fact, it is evident how fine to coarse sand grain sizes feature higher reflectance in the whole spectrum compared to gravel grain sizes. At larger wavelength more sediment classes can be differentiated. Overall, Figure 4 confirms the hypothesis of an inverse correlation between surface grain size and reflectance data.

\subsection{Calibration of the grain size predictive model from Sentinel 2 multispectral data}

Linear (Huber regression) and nonlinear (Random Forest, DNN) regression models were trained, where response variables are the 4597 grain size values, and predictor variables are the 10 bands corresponding Sentinel 2 reflectance values. Table 2 reports the performance metrics resulting from the calibrated models.

Table 2. Results for different modeling techniques for the train and test set. 10 bands used as predictor variables. ME is Mean Error; MAE is Mean Absolute Error.

\begin{tabular}{lllllll}
\hline All bands & \multicolumn{5}{c}{ Train set } & \multicolumn{5}{l}{ Test set } \\
\hline & $\mathrm{R}^{2}$ & MSE & MAE $(\mathrm{mm})$ & $\mathrm{R}^{2}$ & MSE & MAE (mm) \\
\hline Huber Regression & 0.92 & 15.56 & 2.85 & 0.91 & 16.73 & 2.95 \\
Random Forest & 0.98 & 2.16 & 0.72 & 0.97 & 5.20 & 1.06 \\
DNN & 0.86 & 346.7 & 12.76 & 0.88 & 351.47 & 12.86 \\
& & & & & & \\
\hline
\end{tabular}

The test set is used to assess the models. All models perform reasonably well, revealing robustness in the fitting and suitability of the dataset. The coefficient of determination $R^{2}$ is quite high in any model, ranging from 0.92 to 0.98 for Random Forest. The absence of large errors can be noticed, and the Mean Absolute Error (MAE) and the Mean Squared Error (MSE) remain stable between the test data and the training data.

The Huber regressor was chosen to be the most appropriate for the purpose of this study because: model performance in calibration, stability, absence of outliers, insights into the physical explanation behind the observed phenomena, model performance in application, and computational time. The Random Forest model was abandoned because of overfitting issues linked to the strong non-linearity of the model and its tendency to learn the noise in 
data rather than an overall trend. Figure 6 shows the well-fitting of the Huber regression model, resulting in predicted values close to the observed data values. Results show a suitable predictive performance, which is similar for all the sites thus indicating that the model is consistent and robust.

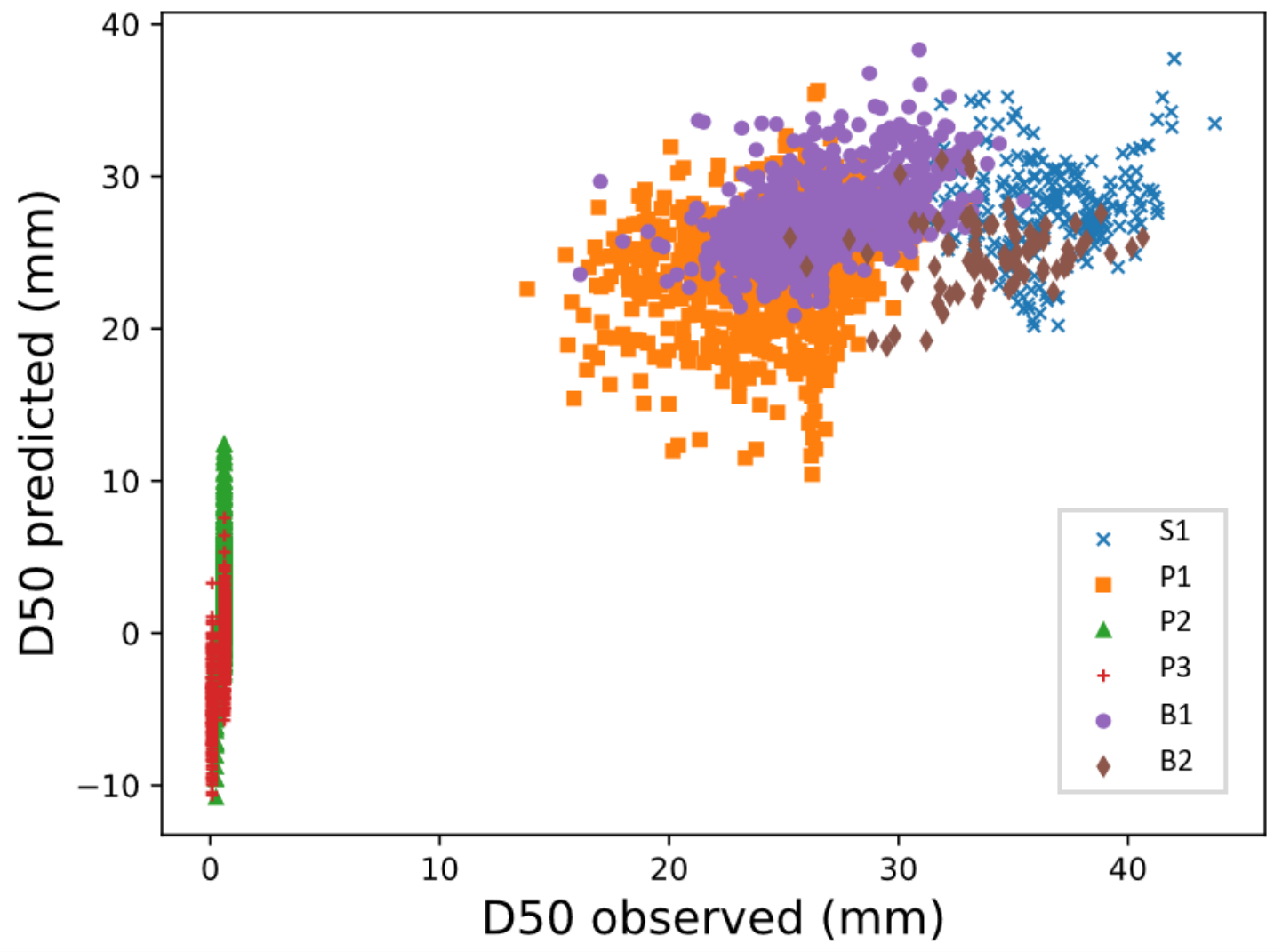

Figure 6. Observed versus predicted $D_{50}$ for the Huber Regressor model with all bands as predictor variables. Reflectance values vs. $D_{50}$ observed diameter. Each site is distinguishable by a different color.

The Huber regression model performs to within $\pm 2.85 \mathrm{~mm}$ for $\mathrm{D}_{50}$. To this value it needs to be added the error of which the grain size dataset is affected, as derived from the texturebased model (MAE for $5.51 \mathrm{~mm}$ ). Thus, the overall error in prediction is $\pm 8.36 \mathrm{~mm}$. Nonetheless, a gap in the dataset is present in the grain size range $1-10 \mathrm{~mm}$, as investigated bars were either finer or coarser than these sizes. Looking at the sand class data some sand particles diameters are assigned with a negative value. This has no physical meaning but is explained by the total error of about $10 \mathrm{~mm}$ of the model and by the linear model functioning. 
A linear regression learns a model which is a linear combination of features of the input examples. In table 3 the coefficients of each band in the linear combination are reported.

Table 3. Coefficients of the bands in the multiple linear regression model

\begin{tabular}{llllllllll}
\hline B2 & B3 & B4 & B5 & B6 & B7 & B8 & B8A & B11 & B12 \\
\hline-193.1 & 104.0 & 59.2 & 242.7 & 196.4 & 127.9 & -213.0 & -36.98 & 41.78 & -356.8 \\
\hline
\end{tabular}

Among all the wavelengths analyzed, the SWIR band B12 has the highest (negative) coefficient, which reveals the significance of this band in the model and the inverse correlation with the grain size. The B8 band in the NIR region seems also quite important, still with a negative relation with sediment size. All other bands appear to contribute to the regression with different signs. However, it is noteworthy that if we look at the results of single linear regression model (i.e., each Sentinel2 band used as single and unique input for the classification model), each single band show a negative coefficient (Table 4).

Table 4. Correlation of each band with the $D 50$ diameter $(\mathrm{mm})$ expressed as coefficient of correlation $(R)$, coefficient of determination $\left(R^{2}\right)$, and related correlation coefficients.

\begin{tabular}{lllllllllll}
\hline & B2 & B3 & B4 & B5 & B6 & B7 & B8 & B8A & B11 & B12 \\
\hline$R$ & -0.65 & -0.54 & -0.5 & -0.56 & -0.57 & -0.6 & -0.58 & -0.61 & -0.73 & -0.81 \\
\hline$R^{2}$ & 0.3 & 0.06 & 0.07 & 0.09 & 0.1 & 0.2 & 0.2 & 0.2 & 0.4 & 0.6 \\
\hline Coeff & -315.4 & -264.8 & -234 & -224.8 & -221 & -212.9 & -199.6 & -207.9 & -164.3 & -145.9 \\
\hline
\end{tabular}

In table $4, \mathrm{R}^{2}$ and coefficient of the regression and the correlations between grain sizes and each band reflectance values are reported. This analysis shows that for all bands there is a certain degree of inverse correlation with the median diameter, confirming the most important physical effect behind the observed trend. Moreover, it shows that the most meaningful bands ( $R^{2}$ values above 0.4$)$ are in the SWIR region, coherently with the results obtained with the model using all bands as input (see Table 2 and 3). More parsimonious model calibrations with two or three bands as input were also attempted. The 10 bands model was used in this study, because it achieves the best model performance compared 
to model with selected bands and because we did not see any specific reason to remove one band compared to another.

Logistic Regression models were also trained on the $80 \%$ of the dataset to discriminate between fine (sand) and coarse (gravel) patches. In table 5 the confusion matrix is reported, resulting from the test set composed of 920 grain size values, which summarizes the performance of the binary classification model (based on $2 \mathrm{~mm}, 22.6$ and $32 \mathrm{~mm}$ as thresholds).

Table 5. Logistic regression results

$\mathrm{D} 50>2 \mathrm{~mm}$ (predicted) $\mathrm{D} 50<2 \mathrm{~mm}$ (predicted)

\begin{tabular}{lll}
\hline D50 $>2 \mathrm{~mm}$ (actual) & 348 & 86 \\
D50 $<2 \mathrm{~mm}$ (actual) & 0 & 486 \\
\hline
\end{tabular}

D50 $>22.6 \mathrm{~mm}$ (predicted) $\mathrm{D} 50<22.6 \mathrm{~mm}$ (predicted)

\begin{tabular}{lcr}
\hline D50 $>22.6 \mathrm{~mm}$ (actual) & 271 & 108 \\
D50 $<22.6 \mathrm{~mm}$ (actual) & 15 & 526
\end{tabular}

D50 $>32 \mathrm{~mm}$ (predicted) $\quad \mathrm{D} 50<32 \mathrm{~mm}$ (predicted)

\begin{tabular}{lll}
\hline $\mathrm{D} 50>32 \mathrm{~mm}$ (actual) & 0 & 59 \\
$\mathrm{D} 50<32 \mathrm{~mm}$ (actual) & 0 & 861
\end{tabular}

The confusion matrix shows that of the 433 data that were greater than $2 \mathrm{~mm}$, the model classified 85 as lower the threshold, so we have 348 true positives (TP) and 85 false negative. With regards to the finer class, the total number of data were correctly classified $(\mathrm{TP}=487)$. Model performance assessment shows that $2 \mathrm{~mm}$ is a good threshold for a 
binary classification. Threshold of $22.6 \mathrm{~mm}$ revealed to have poorer performances and that of $32 \mathrm{~mm}$ revealed to be not suitable for a binary classification.

\subsection{Application of the predictive model to large spatial scales}

Figure 7 shows the downstream variation in the grain size as predicted by the Huber regression model on 10 bands (see section 3.3) along $300 \mathrm{~km}$ of the Po River. The model was applied using the reflectance values of Sentinel 2 data, collected on the $14^{\text {th }}$ of September 2020. As explained above, the linear model gives some negative values for finer particles, that were removed and not considered in the application results.

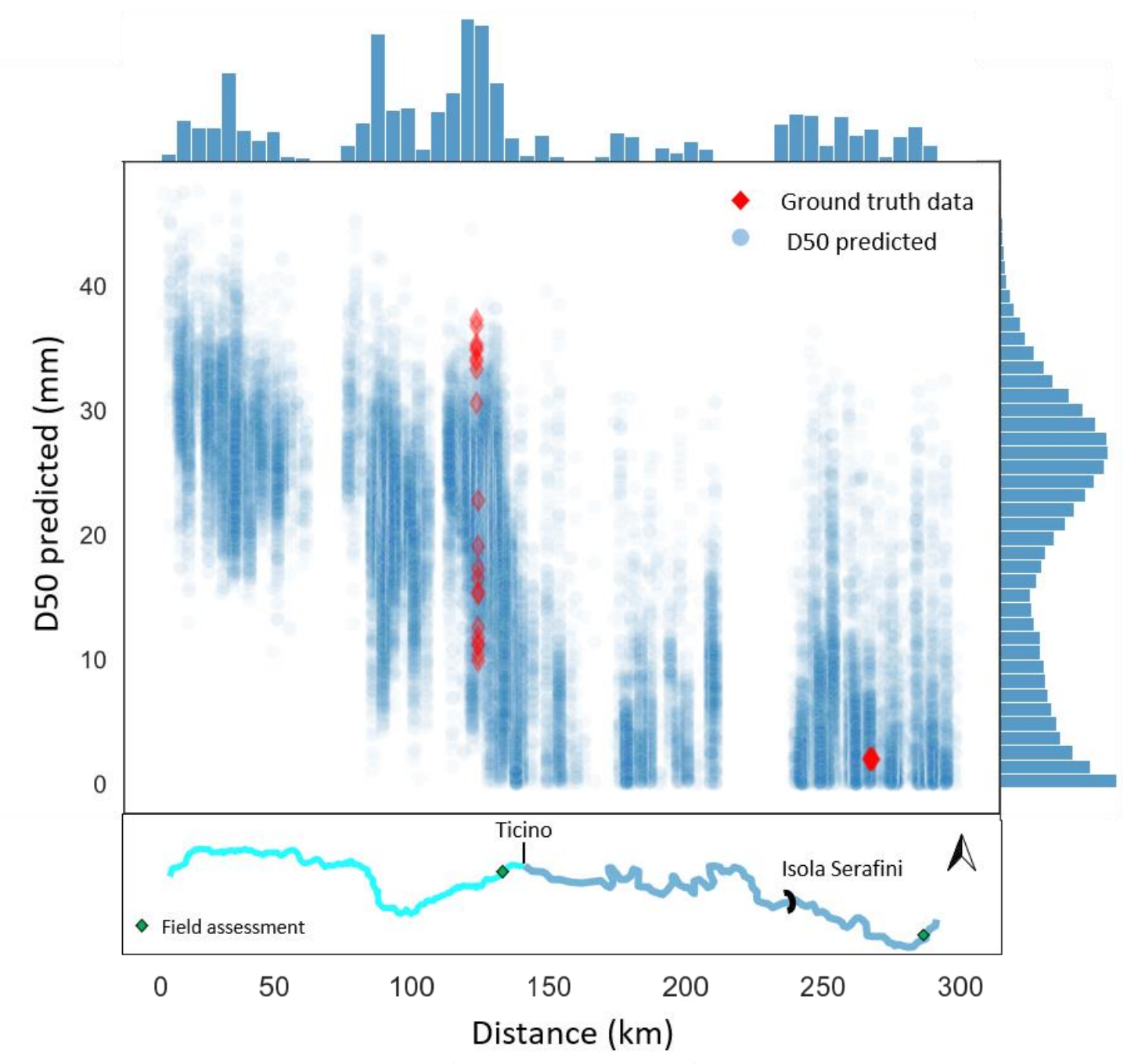

Figure 7. Results of downstream fining modelling on $300 \mathrm{~km}$ of the Po River, from Torino city to Cremona city, using the Huber regression model with 10 bands. Blue points are the median diameter predicted in each pixel (Sentinel 2 dimension) belonging to sediment bars. Red diamonds refer to 
the $D_{50}$ values measured by the ground-truthing methods. All pixels in each bar are assigned with a value for downstream distance. Below, a sketch of the Po river course is shown. Green diamonds show the location where a qualitative assessment was conducted to validate the model prediction.

Model application shows a significant, abrupt decrease in the surface sediment grain size in the Po River around $140 \mathrm{~km}$ downstream from Torino, just below the confluence with the Ticino River. Here, over a relatively short downstream distance, the bed material changes from gravel to sand. This clear gravel-sand transition has been assessed also in the field.

Two wide sediment size distributions are well distinguishable upstream and downstream the gravel-sand transition, the former features a modal value around $28 \mathrm{~mm}$, whereas the latter around $0.1 \mathrm{~mm}$. Regarding the gravel bars, the UAV-based ground truth data confirm the range predicted by the model, and the model seems to reasonably represent the actual grain size heterogeneity of such bars. In contrast, $D_{50}$ values predicted on the sand dominated bars, differ more considerably in terms of $D_{50}$ variations from the (few) values derived from lab sieving of field samples. However, the presence of a small fraction of gravel on these bars was confirmed by field evidence assessment. The explanation of this variability and possible other sources of uncertainty in the sand bars will be discussed further in the following section (see section 4.2 ). Nevertheless, the total average error in prediction is \pm 8.4 $\mathrm{mm}$.

\section{DISCUSSION}

\subsection{Feasibility of orbital grain size mapping of sediment size classes from Sentinel-2 imagery}

In this study we have demonstrated the existence of significant correlations between reflectance intensity in various bands of Sentinel 2 imagery and the D50 fractions of the surface sediment grain size. Robust predictive models were built, which allowed us to estimate particle size classes from orbital data, within an error of $\pm 8.36 \mathrm{~mm}$. Therefore, orbital grain size mapping of sediment classes from Sentinel-2 data is possible thanks to an inverse correlation between radiance values of satellite data and particle size dimension. In fact, the spectral signatures analysis revealed that different sediment classes are distinguishable over the electromagnetic spectrum. This is in accordance with a study on the reflectance properties of 240 types of soils made by Swain and Davis (1978) showing that all soils have a typical reflectance shape, but they may vary in a quite large range, 
depending on several parameters such as soil texture (percentage of sand, silt and clay), soil moisture content (dry, moist, saturated), organic matter content, iron-oxide content, lithology and surface roughness. The spectral analysis made on our dataset, showed that the sediment bars selected on the Bonamico River, featured by a $D_{50}$ of $35 \mathrm{~mm}$, have a lower spectral signature over the whole spectrum, in comparison to the other sites (Fig. 5a). This can be explained by the different factors that influences spectral response of soils. For instance, the Bonamico River is characterized by different lithological conditions (substrate dominated by dark metamorphic and sedimentary rocks) compared to the other study rivers (mainly dominated by lighter-colored metamorphic rocks). Moreover, it is located in a different region strongly different for climate and hydrological conditions. The dataset collected in the different sites, split into sediment classes, have well distinguishable spectral signatures, as far as we move towards longer wavelength (Fig 5b). These results confirm that besides many parameters that influence reflectance response, surface roughness of unvegetated, homogeneous, exposed sediment river bars affect Sentinel-2 data enough to discriminate different sediment classes. The extent to which all factors play a role in the spectral signature response is considered beyond the remit of this study and its principal aim of establishing the feasibility and limits of orbital grain-size mapping.

All models, linear and nonlinear, showed a very high correlation $\left(R^{2}\right)$ which ranges from as high as 0.98 for RF to 0.92 for Huber Regression. The latter model was chosen for further investigations. Indeed, linear models rarely overfit and the Huber regression is thus preferable. A simpler model with comparable performance to more complex one is always more suitable for results interpretation and understanding of the observed phenomena.

In the result section are reported the results of the Huber regressor model calibrated with 10 bands. Most important bands are those in the SWIR and NIR region, coherently with previous studies of Pilorget et al., 2016, Carson et al. (2015), Black et al., 2014). Moreover, the negative coefficients appearing in single band models confirm that the physical effect of an inverse correlation between grain size and reflectance values of Sentinel 2 (Table 4) is likely the most influential physical processes to be captured. The selected multiple linear regression model features some bands with a positive coefficient, notably bands in the same spectral region (because of the higher correlation between them). It is likely that those bands, appearing with positive sign, are related to the other factors that influence reflectance response, such as lithological or climate conditions. We also trained models with selected 
combinations of bands but, so far, we argue that it is still too early to identify an optimal configuration of bands leading to a so-called 'best' predictive model and we proceeded with the 10 bands model as it achieved the best performance both in model training and application.

Logistic regression shows that the binary classification of particles lower and greater the threshold of $2 \mathrm{~mm}$ performed very well. The performance metric precision account for 0.85 , the accuracy metric is 0.91 . This confirms the first statement made that orbital grain size mapping from Sentinel 2 data is possible in terms of sediment classes (sand and gravel). Beyond grain size classes measurement with an error of $\pm 8.4 \mathrm{~mm}$, Sentinel 2 multispectral data can then be used in a binary classification of sand versus gravel dominated river segments.

There are also constrains and limitations in the method which need to be taken into consideration. Sentinel 2 pixels need to be selected carefully based on specific criteria: i) satellite images need to be acquired on days not close to rainfall events since surface wetness influences reflectance values; ii) the Sentinel 2 pixel needs to capture a zone of bare sediment, homogeneous in terms of particle size and with no vegetation or water patches in the $20 \times 20 \mathrm{~m}$ analyzed area. Filters are needed to delete contaminated pixels and separate bright patches where the intensity is driven by sub-pixel scale vegetation from those patches where the intensity is driven by finer particle sizes. This condition is not always easy to meet. In this work we used the Fuzzy classifier outputs (Carbonneau et al. 2020) by setting the 95 value as a threshold. Other thresholds were tested and worked well but we preferred to remain conservative. Moreover, we chose to use computationally expensive super-resolution to get the best possible results from the fuzzy classifier. However, a simplified fuzzy model, generated with only Sentinel-2 bands 2,3,4 and 8, could be used instead (as demonstrated in Carbonneau et al., 2020), thus bypassing the need for the computationally expensive super-resolution.

Another crucial aspect of the study is the atmospheric correction step. Indeed, the scale of intensity changes that are caused by particle size variations could conceivably be completely masked by a poor atmospheric correction. In this study we used atmospherically corrected products of Sentinel 2 available as level 2A products. Moreover, model calibration was tested using products downloaded from the Theia catalogue, resulting from the use of the MACCS-ATCOR Joint Algorithm (MAJA) for the atmospheric correction (Lonjon et al., 
2016), and the performance were comparable. This further analysis gives more strength to our outputs since we can exclude that our outcomes are strictly dependent on the atmospheric correction type conducted.

\subsection{Model applications: D50 pattern generated and qualitative field evidence}

The model reproduces the large-scale downstream fining pattern along $300 \mathrm{~km}$ of the Po River. Predictions are made within an error of around $10 \mathrm{~mm}$ and are well validated by ground truth data (especially those located before the Ticino river confluence).

Close to the Ticino river confluence, the model identifies the gravel-sand transition. In this area it was expected to have an intervening reach, evidenced by a change in the channel morphology from wandering, gravel-dominated bed to sinuous, sand-dominated one. This morphological transition is clearly visible from Google satellite and confirmed in the technical report of the Autorità di bacino del fiume Po, 2007. In addition, a field assessment was conducted to validate model predictions and gravel sand transition detection. Figure 8 shows an example of a bar selected on the gravel sand transition zone, at around $10 \mathrm{~km}$ before the Ticino River confluence.

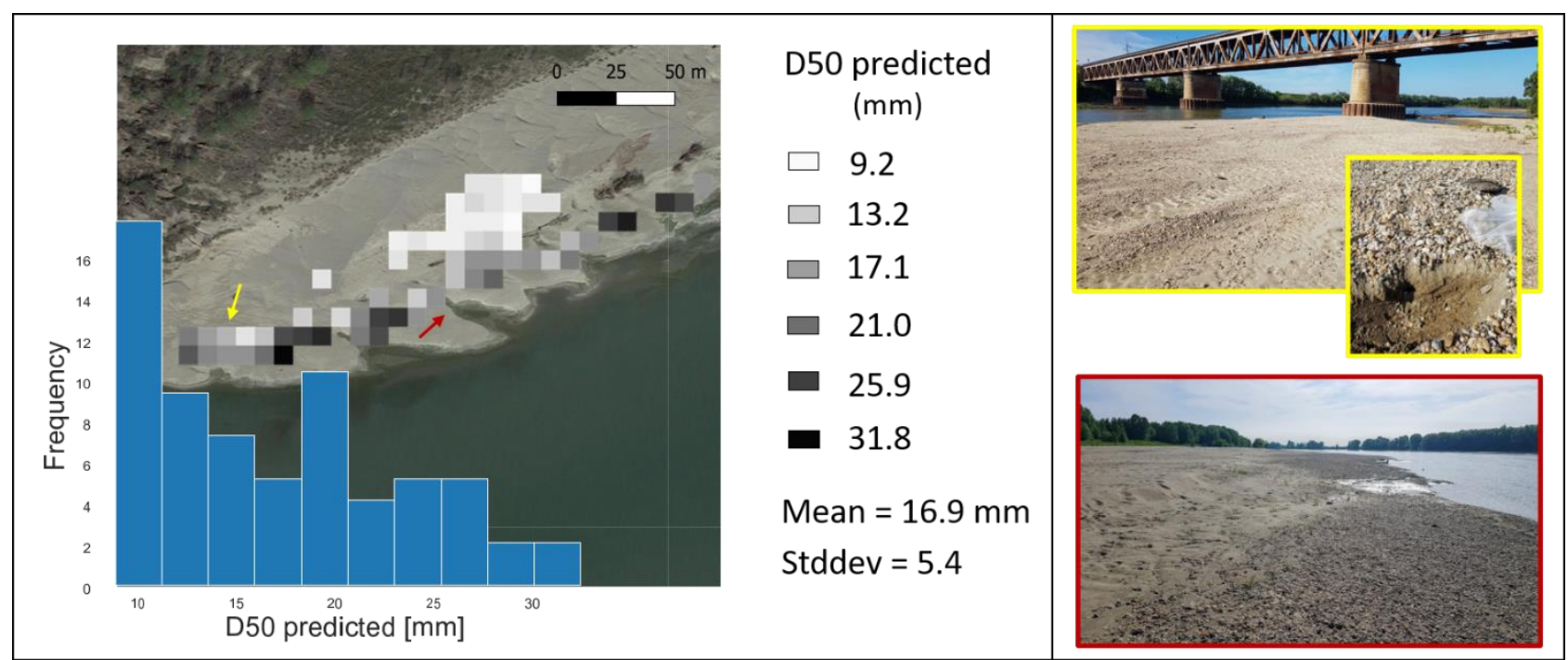

Figure 8. Field assessment on a river bar selected in the transitional zone. On the left, grain size predicted expressed as frequency distribution as well as by gray color scale of the pixels (10x10 m) on the bar. On the right pictures taken in the field.

Figure 8 shows the grain size predicted by the model, the spatial distribution on the sediment bar and the frequency distribution of predicted values. Photos taken in the field confirm the 
spatial arrangement and the values predicted by the model. Usually, through the intervening reach, a bimodal bed material composition is expected (Sambrook Smith and Ferguson, 1995; Ferguson et al., 2011). As shown in the pictures, the surface material on the bar is alternately unimodal sand or gravel, and bimodal gravel-sand mixture. Areas covered by coarse surface layer with sand in the sub-surface are present on the bar head while sand surface and subsurface dominate downstream, where gravel patches are found only close to the water channel. Two sediment samples representative of the bimodal distribution found in the bar were collected on the bar and sieved in the laboratory (total of $4.1 \mathrm{~kg}$ of gravel material and of $1.4 \mathrm{~kg}$ of sand). Results of the sieving show that the gravel sample features a $D_{50}$ of $13.94 \mathrm{~mm}$ and the sand sample of 0.67 . These values validate the prediction made by the model, accounting for the total error of $\pm 8.4 \mathrm{~mm}$.

A second field assessment was conducted on a sand dominated river bar, located downstream the Isola Serafini dam. On this bar as well as on other sand bar along this river reach, a small fraction of gravel is predicted by the model over a few pixels.

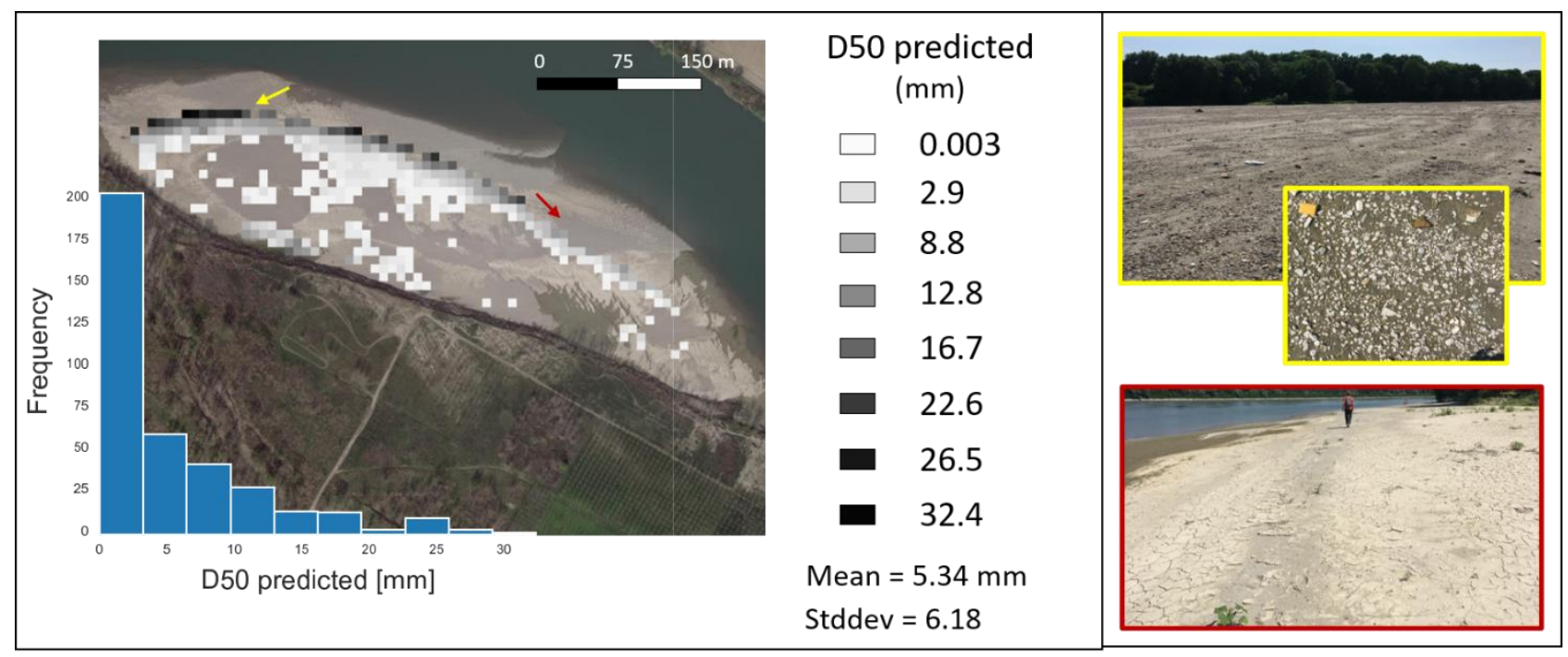

Figure 9. Field assessment on a sand dominated bar selected downstream Isola Serafini dam. On the left, grain size predicted express as frequency distribution as well as by gray color scale of the pixels $(10 \times 10 \mathrm{~m})$ in the bar. On the right pictures taken in the field.

As it can be seen from the histograms in Figure 9, most of the pixels are predicted as sand, and very few data are measured as greater than $15 \mathrm{~mm}$. It can be noticed that the coarser particles (black color) predicted follow a specific spatial distribution pattern, being all located at the border of the bars, close to the water channel. This pattern is found for all sand bars selected along the Po river length. In Figure 9 is reported just a zoom of the bar examined 
in the field, as an example. The field campaign confirmed the grain size data distribution predicted and the presence of coarser material close to the river channel, as evident from the pictures. The occurrence of gravel in this river reach is in truth not surprising and is also confirmed in the technical report made by the Autorità di bacino del Fiume Po, 2007. Indeed, along this river length, several important tributaries coming from the Apennines mountain chain, such as Enza, Trebbia, Taro, bring coarse material and high sediment supply to the main channel. However, because of the deep and narrow channel, the river channel is sinuous, with alternate sand bars. The coarser material coming from the tributaries is likely transported at the bottom of the water channel. Its presence is revealed on the sand dominated bars by surface patches of coarser material, close to the water channel.

\subsection{Future Developments}

New model calibration would be useful to give more robustness to the model and test it on sediment classes not included in this work (notably from 1 to $10 \mathrm{~mm}$ and particles in the range of pebbles/boulders). With the use of a low-cost commercial drone and calibration with the grain size mapping methods of (Carbonneau et al., 2018; Woodget et al., 2018), this will require little effort in terms of time and costs. A data-driven approach able to measure grain size distributions from georeferenced UAV images on entire river bars, centered on linear regression model such that used in this work or more complex deep learning model such as convolutional neural network (Lang et al., 2021) will allow for rapidly enlarge the dataset. The inclusion of other particles fraction such as D84 and D16 would also be interesting for a more detailed grain size distribution analysis. So far, with the objective of sediment classes discrimination, the $D_{50}$ diameter was considered suitable and exhaustive.

The ability of the model to reproduce large-scale downstream fining patterns, including gravel-sand transition identification, was shown for the Po River. Model application was made on a date (14 ${ }^{\text {th }}$ of September 2020) selected with good hydrological and climate conditions, in a year (2020) in between 2018 and 2021 (date of the field work activities). Other dates were also tested in 2018 and 2021 and the reproduced grain size variations are comparable (e.g. gravel sand transition identification) and follow the same explanations presented. Future analysis will apply the model in several dates to study the seasonal/annual trends. The gravel sand transition identification is a main finding of the 
model application and show the potential of this model in mapping and monitoring river processes at the catchment scale. Being able to map grain size classes and to detect transitional zones through time can support river processes understanding (Smith and Ferguson 1995, Knighton, 1999; Ferguson, 2003; Topping et al., 2018, Frings, 2011, Venditti and Church 2014) and answer questions such as: Where is the gravel-sand transition and what is its morphology? Which factors are causing a change in sediment composition and/or in the transition to migrate downstream/upstream?

It is clear that, because of the limitation of Sentinel 2 resolution data, only large river bars can be investigated with this model. Considering Sentinel 2 data characteristics (10 m spatial resolution), following Downing et al., 2012 insights, this methodology is applicable to streams of at least $5^{\text {th }}-6^{\text {th }}$ order (correspondent mean stream width of $29.3 \mathrm{~m}$ and $73.3 \mathrm{~m}$ ) which represent roughly $71 \%$ of the world riverine catchment area. This is a strong indicator that a large-scale monitoring methodology is required for river systems.

Given the open-access nature of Sentinel 2 data and the high temporal frequency, the method can be applied through time and to other river systems to measure long-term changes in grain size classes along hundreds of kilometers of river lengths. Mapping these precious data at such large temporal and spatial scale is fundamental to integrate emerging network-scale global monitoring and modeling (Pekel et al., 2016; Allen and Pavelsky 2018, Mouyen et al., 2018, Tangi et al. 2019, Schmitt et al., 2019) and to support watermanagement decision-making.

Moreover, the collected dataset could be used as training data to test the potential of other satellites data (e.g. radar, Purinton and Bookhagen, 2020 and hyperspectral) to be used in combination with the multispectral data.

Finally, this approach can find novel application on the grain size data characterization of other open natural environment where an automatized sediment composition characterization is meaningful for earth surface processes understanding. New perspectives on natural environment both in plain and mountain areas (Williams and Brierley 2019, Coviello et al., 2021, Trevisani and Cavalli 2016, Kofler et al., 2021) are worth to be investigated in the future. 


\section{CONCLUSION}

We believe that the most important contribution of this paper is the first orbital grain size mapping of sediment classes from freely available Sentinel 2 data. This is a fundamentally new area of remote sensing which will allow for grain size characterization of sand and gravel sediment classes of very long reaches $(>100 \mathrm{~km})$ at very low costs.

In this paper, we used near-ground UAV imagery to calibrate robust linear correlations between the grain sizes, $D_{50}(\mathrm{~mm})$, on dry exposed river bars and reflectance values in Sentinel 2 imagery. We obtained statistically significant predictive models for $D_{50}$, able to predict, within an error of about $10 \mathrm{~mm}$, sediment grain size classes in the range of sand and gravel. Used in prediction, this model reproduced the expected downstream fining trends for a $300 \mathrm{~km}$ long stretch of the River Po in Northern Italy, notably identifying the gravel sand transition occurring along the river length.

\section{ACKNOWLEDGEMENTS}

This work was performed in the framework of the "IRIS - Italian Research and development Initiative for Spaceborne river monitoring", https://www.isprambiente.gov.it/pre_meteo/idro/idro.html\#HabitatMapping, funded in the context of the Italian Space Agency-ISPRA initiative "Habitat Mapping". The authors are grateful to the EU Copernicus Programme for providing Sentinel 2 L2A data and to Theia for making available MAJA corrected Sentinel 2 data. We thank Dr. Martina Bussettini, Dr. Stefano Mariani, Mr. Marco Casaioli and Ms. Francesca Piva for DJI Phantom 4 Pro and Trimble R10 RTK-GPS acquisitions during ground fields. We also thank colleagues Andrea Andreoli and Velio Coviello for the support in the field and in the laboratory. Finally, thanks to Prof Andrea Francesco Castelletti for the support at the beginning of this work at Politecnico di Milano, Milan, Italy. B. Belletti contribution was in part supported by the EUR H2O'Lyon (ANR-17-EURE-0018). 


\section{References}

1 Allen, George H., and Tamlin M. Pavelsky. "Global Extent of Rivers and Streams." Science, August 10, 2018. https://www.science.org/doi/abs/10.1126/science.aat0636.

Autorità di bacino del fiume Po. "Aggiornamento Delle Analisi Morfologiche e Del Bilancio Del Trasporto Solido Dell'asta Del Fiume Po Da Confluenza Stura Di Lanzo All'incile Del Delta (Periodo 2002 - 2005) e Report Di Valutazione," 2007.

6 Black, Martin, Patrice Carbonneau, Michael Church, and Jeff Warburton. "Mapping Sub7 Pixel Fluvial Grain Sizes with Hyperspatial Imagery." Sedimentology 61, no. 3 (April 1, 8 2014): 691-711. https://doi.org/10.1111/sed.12072.

9 Brodu, Nicolas. "Super-Resolving Multiresolution Images With Band-Independent Geometry 10 of Multispectral Pixels." IEEE Transactions on Geoscience and Remote Sensing 55, no. 8 11 (August 2017): 4610-17. https://doi.org/10.1109/TGRS.2017.2694881.

12 Buscombe, D., D. M. Rubin, and J. A. Warrick. "A Universal Approximation of Grain Size 13 from Images of Noncohesive Sediment." Journal of Geophysical Research: Earth Surface 14 115, no. F2 (June 1, 2010): F02015. https://doi.org/10.1029/2009JF001477.

15 Buscombe, Daniel, and Gerhard Masselink. "Grain-Size Information from the Statistical 16 Properties of Digital Images of Sediment." Sedimentology 56, no. 2 (February 1, 2009): 421 17 38. https://doi.org/10.1111/j.1365-3091.2008.00977.x.

18 Busetto, Lorenzo, Michele Meroni, and Roberto Colombo. "Combining Medium and Coarse 19 Spatial Resolution Satellite Data to Improve the Estimation of Sub-Pixel NDVI Time Series." 20 Remote Sensing of Environment 112, no. 1 (January 15, 2008): 118-31. 21 https://doi.org/10.1016/j.rse.2007.04.004.

22 Carbonneau, Patrice E., Belletti Barbara, Micotti Marco, Lastoria Barbara, Casaioli Marco, 23 Mariani Stefano, Marchetti Giulia, and Bizzi Simone. "UAV-Based Training for Fully Fuzzy 24 Classification of Sentinel-2 Fluvial Scenes." Earth Surface Processes and Landforms 45, 25 no. 13 (2020): 3120-40. https://doi.org/10.1002/esp.4955.

26 Carbonneau, Patrice E., Normand E. Bergeron, and Stuart N. Lane. "Texture-Based Image 27 Segmentation Applied to the Quantification of Superficial Sand in Salmonid River Gravels." 28 Earth Surface Processes and Landforms 30, no. 1 (2005): 121-27. 29 https://doi.org/10.1002/esp.1140. 
30 Carbonneau, Patrice E., Normand Bergeron, and Stuart N. Lane. "Automated Grain Size

31 Measurements from Airborne Remote Sensing for Long Profile Measurements of Fluvial

32 Grain Sizes." Water Resources Research 41, no. 11 (November 1, 2005): W11426.

33 https://doi.org/10.1029/2005WR003994.

34 Carbonneau, Patrice E., Stuart N. Lane, and Normand E. Bergeron. "Catchment-Scale 35 Mapping of Surface Grain Size in Gravel Bed Rivers Using Airborne Digital Imagery." Water 36 Resources Research 40, no. 7 (July 1, 2004): W07202. 37 https://doi.org/10.1029/2003WR002759.

38 Carbonneau, P.e., S. Bizzi, and G. Marchetti. "Robotic Photosieving from Low-Cost 39 Multirotor SUAS: A Proof-of-Concept." Earth Surface Processes and Landforms, n.d., n/a40 n/a. https://doi.org/10.1002/esp.4298.

41 Carson, Tyler, Charles M. Bachmann, and Carl Salvaggio. "Soil Signature Simulation of 42 Complex Mixtures and Particle Size Distributions." Optical Engineering 54, no. 9 (September

Coviello, Velio, Joshua I. Theule, Stefano Crema, Massimo Arattano, Francesco Comiti, Marco Cavalli, Ana Lucĺa, Pierpaolo Macconi, and Lorenzo Marchi. “Combining Instrumental Monitoring and High-Resolution Topography for Estimating Sediment Yield in a Debris-Flow 2 Catchment." Environmental and Engineering Geoscience 27, no. 1 (December 2, 2020): 953 111. https://doi.org/10.2113/EEG-D-20-00025.

4 Detert, M, and V Weitbrecht. "Automatic Object Detection to Analyze the Geometry of Gravel 5 Grains - a Free Stand-Alone Tool." River Flow 2012 (2012): 595-600.

56 Downing, J.A., J.J. Cole, C.M. Duarte, J.J. Middelburg, J.M. Melack, Y.T. Prairie, P. 57 Kortelainen, R.G. Striegl, W.H. McDowell, and L.J. Tranvik. "Global Abundance and Size 58 Distribution of Streams and Rivers." Inland Waters 2, no. 4 (January 1, 2012): 229-36. 59 https://doi.org/10.5268/IW-2.4.502. 
60 Dugdale, Stephen J., Patrice E. Carbonneau, and David Campbell. "Aerial Photosieving of

61 Exposed Gravel Bars for the Rapid Calibration of Airborne Grain Size Maps." Earth Surface

62 Processes and Landforms 35, no. 6 (May 1, 2010): 627-39.

63 https://doi.org/10.1002/esp.1936.

64 Fausch, Kurt D., Christian E. Torgersen, Colden V. Baxter, and Hiram W. Li. "Landscapes 65 to Riverscapes: Bridging the Gap between Research and Conservation of Stream Fishes." 66 BioScience 52, no. 6 (June 1, 2002): 483-98. https://doi.org/10.1641/000667 3568(2002)052[0483:LTRBTG]2.0.CO;2.

68 Ferguson, R. I., D. J. Bloomer, and M. Church. "Evolution of an Advancing Gravel Front: 69 Observations from Vedder Canal, British Columbia." Earth Surface Processes and 70 Landforms 36, no. 9 (2011): 1172-82. https://doi.org/10.1002/esp.2142.

71 Ferguson, Rob, Trevor Hoey, Simon Wathen, and Alan Werritty. "Field Evidence for Rapid 72 Downstream Fining of River Gravels through Selective Transport." Geology 24, no. 2 73 (February 1, 1996): 179-82. https://doi.org/10.1130/009174 7613(1996)024<0179:FEFRDF>2.3.CO;2.

75 Frings, Roy M., Willem Ottevanger, and Kees (C.J.) Sloff. "Downstream Fining Processes 76 in Sandy Lowland Rivers." Journal of Hydraulic Research 49, no. 2 (April 1, 2011): 178-93. 77 https://doi.org/10.1080/00221686.2011.561000.

78 Graham, David J., Ian Reid, and Stephen P. Rice. "Automated Sizing of Coarse-Grained 79 Sediments: Image-Processing Procedures." Mathematical Geology 37, no. 1 (January 1, 80 2005): 1-28. https://doi.org/10.1007/s11004-005-8745-x.

81 Graham, David J., Anne-Julia Rollet, Hervé Piégay, and Stephen P. Rice. "Maximizing the 82 Accuracy of Image-based Surface Sediment Sampling Techniques." Water Resources 83 Research 46, no. 2 (February 1, 2010). https://doi.org/10.1029/2008WR006940.

84 Gumiero, B., N. Surian, B. Maiolini, B. Boz, M. Rinaldi, and F. Moroni. "Chapter 12 - The 85 Italian Rivers." In Rivers of Europe, edited by Klement Tockner, Urs Uehlinger, and 86 Christopher T. Robinson, 467-95. London: Academic Press, 2009. 87 https://doi.org/10.1016/B978-0-12-369449-2.00012-6.

88 Hapke, Bruce. "Bidirectional Reflectance Spectroscopy: 3. Correction for Macroscopic 89 Roughness." Icarus 59, no. 1 (July 1, 1984): 41-59. https://doi.org/10.1016/001990 1035(84)90054-X. 
91 Knighton, A. David. "The Gravel-Sand Transition in a Disturbed Catchment." 92 Geomorphology 27, no. 3 (March 1, 1999): 325-41. https://doi.org/10.1016/S0169$93555 \times(98) 00078-6$.

94 Kofler, Christian, Volkmar Mair, Stephan Gruber, Maria Cristina Todisco, lan Nettleton, 95 Stefan Steger, Marc Zebisch, Stefan Schneiderbauer, and Francesco Comiti. "When Do 96 Rock Glacier Fronts Fail? Insights from Two Case Studies in South Tyrol (Italian Alps)." 97 Earth Surface Processes and Landforms 46, no. 7 (2021): 1311-27. 98 https://doi.org/10.1002/esp.5099.

99 Lang, Nico, Andrea Irniger, Agnieszka Rozniak, Roni Hunziker, Jan Dirk Wegner, and 100 Konrad Schindler. "GRAINet: Mapping Grain Size Distributions in River Beds from UAV 101 Images with Convolutional Neural Networks." Hydrology and Earth System Sciences 25, no. 1025 (May 19, 2021): 2567-97. https://doi.org/10.5194/hess-25-2567-2021.

103 Marchetti, Mauro. "Environmental Changes in the Central Po Plain (Northern Italy) Due to 104 Fluvial Modifications and Anthropogenic Activities." Geomorphology, Geomorphology on 105 Large Rivers, 44, no. 3 (May 1, 2002): 361-73. https://doi.org/10.1016/S0169106 555X(01)00183-0.

107 Mouyen, Maxime, Laurent Longuevergne, Philippe Steer, Alain Crave, Jean-Michel 108 Lemoine, Himanshu Save, and Cécile Robin. "Assessing Modern River Sediment Discharge 109 to the Ocean Using Satellite Gravimetry." Nature Communications 9, no. 1 (August 23, 110 2018): 3384. https://doi.org/10.1038/s41467-018-05921-y.

111 Nash, D. B., and J. E. Conel. "Spectral Reflectance Systematics for Mixtures of Powdered 112 Hypersthene, Labradorite, and IImenite." Journal of Geophysical Research (1896-1977) 79, 113 no. 11 (1974): 1615-21. https://doi.org/10.1029/JB079i011p01615.

114 Pedregosa, Fabian, Gael Varoquaux, Alexandre Gramfort, Vincent Michel, Bertrand Thirion, 115 Olivier Grisel, Mathieu Blondel, et al. "Scikit-Learn: Machine Learning in Python." MACHINE 116 LEARNING IN PYTHON, n.d., 6.

117 Pekel, Jean-François, Andrew Cottam, Noel Gorelick, and Alan S. Belward. "High118 Resolution Mapping of Global Surface Water and Its Long-Term Changes." Nature 540, no. 1197633 (December 2016): 418-22. https://doi.org/10.1038/nature20584.

120 Pilorget, C., J. Fernando, B. L. Ehlmann, F. Schmidt, and T. Hiroi. "Wavelength Dependence 121 of Scattering Properties in the VIS-NIR and Links with Grain-Scale Physical and 
122 Compositional Properties." Icarus 267 (March 15, 2016): 296-314.

123 https://doi.org/10.1016/j.icarus.2015.12.029.

124 Pilorget, C., J. Fernando, B.L. Ehlmann, and S. Douté. "Photometry of Particulate Mixtures: 125 What Controls the Phase Curve?" Icarus 250 (April 2015): 188-203. 126 https://doi.org/10.1016/j.icarus.2014.11.036.

127 Pilorget, C., M. Vincendon, and F. Poulet. "A Radiative Transfer Model to Simulate Light 128 Scattering in a Compact Granular Medium Using a Monte-Carlo Approach: Validation and 129 First Applications." Journal of Geophysical Research: Planets 118, no. 12 (December 1, 130 2013): 2488-2501. https://doi.org/10.1002/2013JE004465.

131 Pitlick, John, Erich R. Mueller, Catalina Segura, Robert Cress, and Margaret Torizzo. 132 "Relation between Flow, Surface-layer Armoring and Sediment Transport in Gravel-bed 133 Rivers." Earth Surface Processes and Landforms 33, no. 8 (July 2008): 1192-1209. 134 https://doi.org/10.1002/esp.1607.

135 Pizzuto, James E. "Downstream Fining in a Network of Gravel-Bedded Rivers." Water 136 Resources Research 31, no. 3 (March 1, 1995): 753-59. 137 https://doi.org/10.1029/94WR02532.

138 Purinton, Benjamin, and Bodo Bookhagen. "Introducing PebbleCounts: A Grain-Sizing Tool 139 for Photo Surveys of Dynamic Gravel-Bed Rivers." Earth Surface Dynamics 7, no. 3 140 (September 17, 2019): 859-77. https://doi.org/10.5194/esurf-7-859-2019.

141 Purinton, Benjamin, and Bodo Bookhagen. "Multiband (X, C, L) Radar Amplitude Analysis 142 for a Mixed Sand- and Gravel-Bed River in the Eastern Central Andes." Remote Sensing of 143 Environment 246 (September 1, 2020): 111799. https://doi.org/10.1016/j.rse.2020.111799.

144 Rice, Stephen P., and Michael Church. "Longitudinal Profiles in Simple Alluvial Systems." 145 Water Resources Research 37, no. 2 (February 1, 2001): 417-26. 146 https://doi.org/10.1029/2000WR900266.

147 Robinson, David A., and Shmulik P. Friedman. "Electrical Conductivity and Dielectric 148 Permittivity of Sphere Packings: Measurements and Modelling of Cubic Lattices, Randomly 149 Packed Monosize Spheres and Multi-Size Mixtures." Physica A: Statistical Mechanics and 150 Its Applications 358, no. 2 (December 15, 2005): 447-65. 151 https://doi.org/10.1016/j.physa.2005.03.054. 
152 Rubin, David M. "A Simple Autocorrelation Algorithm for Determining Grain Size from Digital 153 Images of Sediment." Journal of Sedimentary Research 74, no. 1 (January 1, 2004): 160154 65. https://doi.org/10.1306/052203740160.

155 Sambrook Smith, Gregory H., and Robert I. Ferguson. "The Gravel-Sand Transition along 156 River Channels." Journal of Sedimentary Research 65, no. 2a (April 3, 1995): 423-30. 157 https://doi.org/10.1306/D42680E0-2B26-11D7-8648000102C1865D.

158 Schmitt, R. J. P., S. Bizzi, A. Castelletti, J. J. Opperman, and G. M. Kondolf. "Planning Dam 159 Portfolios for Low Sediment Trapping Shows Limits for Sustainable Hydropower in the 160 Mekong." Science Advances 5, no. 10 (October 23, 2019): eaaw2175. 161 https://doi.org/10.1126/sciadv.aaw2175.

162 Surian, Nicola, and Massimo Rinaldi. "Morphological Response to River Engineering and 163 Management in Alluvial Channels in Italy." Geomorphology 50, no. 4 (March 1, 2003): 307164 26. https://doi.org/10.1016/S0169-555X(02)00219-2.

165 Swain, P.H. and S.M. Davis. 1978. Remote sensing: The 166 quantitative approach. McGraw-Hill. New York.

167 Tangi, Marco, Rafael Schmitt, Simone Bizzi, and Andrea Castelletti. "The CASCADE 168 Toolbox for Analyzing River Sediment Connectivity and Management." Environmental 169 Modelling \& Software $119 \quad$ (September 1, 2019): 400-406. 170 https://doi.org/10.1016/j.envsoft.2019.07.008.

171 Topping, David J., Erich R. Mueller, John C. Schmidt, Ronald E. Griffiths, David J. Dean, 172 and Paul E. Grams. "Long-Term Evolution of Sand Transport Through a River Network: 173 Relative Influences of a Dam Versus Natural Changes in Grain Size From Sand Waves." 174 Journal of Geophysical Research: Earth Surface 123, no. 8 (2018): 1879-1909. 175 https://doi.org/10.1029/2017JF004534.

176 Trevisani, Sebastiano, and Marco Cavalli. "Topography-Based Flow-Directional 177 Roughness: Potential and Challenges." Earth Surface Dynamics 4, no. 2 (April 21, 2016): 178 343-58. https://doi.org/10.5194/esurf-4-343-2016.

179 Vázquez-Tarrío, Daniel, Laurent Borgniet, Frédéric Liébault, and Alain Recking. "Using UAS 180 Optical Imagery and SfM Photogrammetry to Characterize the Surface Grain Size of Gravel 181 Bars in a Braided River (Vénéon River, French Alps)." Geomorphology 285 (May 15, 2017): 182 94-105. https://doi.org/10.1016/j.geomorph.2017.01.039. 
183 Venditti, Jeremy G., and Michael Church. "Morphology and Controls on the Position of a 184 Gravel-Sand Transition: Fraser River, British Columbia." Journal of Geophysical Research: 185 Earth Surface 119, no. 9 (2014): 1959-76. https://doi.org/10.1002/2014JF003147.

186 Verdú, Joan M., Ramon J. Batalla, and José A. Martínez-Casasnovas. "High-Resolution 187 Grain-Size Characterisation of Gravel Bars Using Imagery Analysis and Geo-Statistics." 188 Geomorphology 72, no. 1 (December 1, 2005): $73-93$. 189 https://doi.org/10.1016/j.geomorph.2005.04.015.

190 Verhoeye, Jan, and Robert De Wulf. "Land Cover Mapping at Sub-Pixel Scales Using Linear 191 Optimization Techniques." Remote Sensing of Environment 79, no. 1 (January 1, 2002): 96192 104. https://doi.org/10.1016/S0034-4257(01)00242-5.

193 Vincent Lonjou, Camille Desjardins, Olivier Hagolle, Beatrice Petrucci, Thierry Tremas, 194 Michel Dejus, Aliaksei Makarau, and Stefan Auer. "MACCS-ATCOR Joint Algorithm 195 (MAJA)," Vol. 10001, 2016. https://doi.org/10.1117/12.2240935.

196 Walt, Stéfan van der, Johannes L. Schönberger, Juan Nunez-Iglesias, François Boulogne, 197 Joshua D. Warner, Neil Yager, Emmanuelle Gouillart, and Tony Yu. "Scikit-Image: Image 198 Processing in Python." PeerJ 2 (June 19, 2014): e453. https://doi.org/10.7717/peerj.453.

199 Westoby, M. J., J. Brasington, N. F. Glasser, M. J. Hambrey, and J. M. Reynolds. "'Structure200 from-Motion' Photogrammetry: A Low-Cost, Effective Tool for Geoscience Applications." 201 Geomorphology 179 (December 15, 2012): 300-314. 202 https://doi.org/10.1016/j.geomorph.2012.08.021.

203 Williams, R. D., H. E. Reid, and G. J. Brierley. "Stuck at the Bar: Larger-Than-Average Grain 204 Lag Deposits and the Spectrum of Particle Mobility." Journal of Geophysical Research: Earth 205 Surface 124, no. 12 (2019): 2751-56. https://doi.org/10.1029/2019JF005137.

206 Woodget, A. S., C. Fyffe, and P. E. Carbonneau. "From Manned to Unmanned Aircraft: 207 Adapting Airborne Particle Size Mapping Methodologies to the Characteristics of SUAS and 208 SfM." Earth Surface Processes and Landforms 43, no. 4 (2018): 857-70. 209 https://doi.org/10.1002/esp.4285. 